\title{
EFEITO DE DIFERENTES INTENSIDADES DE DESFOLHANA PRÉ-FLORADA SOBRE O CRESCIMENTO VEGETATIVO DO CAFÉ CONILON DE VARIEDADE CLONAL
}

\author{
Manuela Arruda Contarine ${ }^{1}$ \\ Jhonatas Souza Ventura Tosta ${ }^{2}$ \\ Julio Cesar Gradice Saluci ${ }^{3}$ \\ Amós Mendes da Silva ${ }^{4}$ \\ Alex Justino Zacarias ${ }^{5}$ \\ Rebyson Bissaco Guidinelle ${ }^{6}$ \\ Israel Martins Pereira ${ }^{7}$ \\ Telma Machado de Oliveira Peluzio ${ }^{8}$ \\ João Batista Esteves Peluzio9
}

Resumo: O cafeeiro assim como outras culturas mantém a maior parte de suas reservas nas folhas, que resultam na fotossintese e sustentam os seus frutos. O objetivo deste trabalho foi avaliar o efeito da intensidade de desfolha na pré-florada sobre o crescimento e desenvolvimento da planta de café conilon da variedade Vitória, clone $n^{\circ} 7$, sendo desenvolvido no Setor de Cafeicultura do Ifes - campus de Alegre. Utilizou-se o delineamento em blocos casualizados, no arranjo fatorial e subparcelas no tempo, compondo 15 tratamentos e três repetições, considerando 2 plantas úteis por parcela, com uso de bordaduras. O fator desfolha considerou os níveis de 0, 25, 50, 75 e 100\%, realizada no mês de agosto, pré-florada. Em relação as coletas de informações, ao longo do tempo. As características de crescimento analisadas demonstraram diferença em função dos tratamentos, 0, 25, 50 e 75\% que apresentaram resultados estatisticamente iguais, porem na desfolha de $100 \%$ foram encontradas menores médias para todas as variáveis.

Palavras-chave: Cafeeiro; Desenvolvimento; Plantas; Área foliar

\footnotetext{
${ }^{1}$ Instituto Federal do Espírito Santo, Brasil. E-mail: manucontarine@gmail.com.

2 Instituto Federal do Espírito Santo, Brasil. E-mail: jhonatastosta@gmail.com.

3 Instituto Federal do Espírito Santo, Brasil. E-mail: juliosaluci@gmail.com.

4 Instituto Federal do Espírito Santo, Brasil. E-mail: amos_mf13@hotmail.com.

5 Instituto Federal do Espírito Santo, Brasil. E-mail: alexjustino12@gmail.com.

6 Instituto Federal do Espírito Santo, Brasil. E-mail: rebysonguidinelle@gmail.com.

7 Instituto Federal do Espírito Santo, Brasil. E-mail: israelmartins80@gmail.com.

8 Instituto Federal do Espírito Santo, Brasil. E-mail: tmopeluzio@ifes.edu.br.

9 Instituto Federal do Espírito Santo, Brasil. E-mail: jbpeluzio@gmail.com.
} 